\title{
Using Mobile Learning Tools in Higher Education: A UAE Case
}

https://doi.org/10.3991/ijim.v13i11.10823

\author{
Jenny Eppard ${ }^{(\bowtie)}$, Zeina Hojeij, Pinar Ozdemir-Ayber, \\ Marlieke Rodjan-Helder, Sandra Baroudi \\ Zayed University, United Arab Emirates \\ jrk3r@virginia.edu
}

\begin{abstract}
Research indicates that mobile learning (ML), has the potential to transform teaching and learning. Despite its benefits, mobile learning adoption is a challenging process which requires support to facilitate its integration. The focus of this article is to investigate the factors that could affect ML acceptance. The quantitative and qualitative data collected from the surveys revealed additional information regarding the pedagogical benefits of and obstacles to mobile learning integration. Even though participants in this study reported to be late adopters of technology, they maintained that ML is useful for learning, specifically ubiquitous learning. Teachers also noted that mobile learning integration is more successful when aligned with local cultural norms. Mobile learning tools that might be culturally appropriate in one context may not always be accepted in another. Findings of this study provide several implications and recommendations for future research on mobile learning implementation. Further research could explore the development and utilization of a rubric with specific criteria for evaluating mobile learning applictations.
\end{abstract}

Keywords - Mobile Learning, Higher Education, m-adoption, iPad initiative

\section{Introduction}

Mobile technologies possess educational potential for today's generation much like television did 45 years ago. They can encourage ubiquitous learning allowing students to access and process information regardless of time or place. Mobile technologies also have the ability to support collaboration and communication and individualized learning based on personal needs (Bradley \& Holley, 2011; Ranieri \& Pachler, 2014).

Even though ML has signifant potential when used as an educational tool, the literature on Mobile Learning (ML) is dynamic and at times chaotic. Due to the ambiguous nature of mobile learning research, an exact definition of ML has been difficult to develop.Mobile learning has the potential to be private, informal, spontaneous and mobile in a way that e-learning is not (Traxler, 2009). In addition, mobile learning enables users to "access, and experiment with, multimedia and other electronic content for subject-matter instruction, both in and outside the traditional classroom setting” (Wagner et al., 2014, p. 120). Traxler (2009) states that mobile devices include 
the following, "handheld computers, personal digital assistants, camera phones, smartphones, graphing calculators, personal response systems, games consoles and personal media players" (p. 2) and can be "ubiquitous in most parts of the world" (p. 2 ). The ubiquity of these devices possibly supports students' access to learning materials anytime and anywhere leading to an increase in contact with both formal and informal learning. Our definition of ML includes the use of mobile devices, both smartphones and tablets, as a vehicle for the use of educational apps that can be accessed anywhere at anytime given the correct infrastructure.

Research into mobile learning is still developing. Results are promising but often lack reliability; therefore, it is still too early to determine how mobile learning will affect education (Wagner et al., 2014). To date, research includes topics such as using mobile devices as tools for student learning (Ally, 2013; Bradley \& Holley, 2011), for adult learning and for differentiated learning in both developed and developing contexts (Ranieri \& Pachler, 2014; Wagner et al., 2014). Other research includes the benefits of ML towards teachers' education and professional development; (Baran, 2014) and the importance of teachers' adoption of mobile learning and the factors that impact this adoption (i.e., MacCallum, Jeffrey, \& Kinshuk, 2014).

\section{Statement of Problem}

Even though early research into ML indicates several possible benefits, it is best utilized when there is a clear understanding of how it will benefit the overall learning environment and clearly connect to learning objectives (Kerrigan, et al., 2014). While investigating the successulful implementation of ML, numerous variables such as age, learning theory, subject, learning style, culture and infrastructure were considered vital for determining its success (Cheon et al., 2012). Despite the importance of these factors in determining ML effectiveness, more studies are needed internationally to better understand how it is being used and perceived by all stakeholders. Hence, the goal of this research is to explore the perceptions of mobile learning adoption by faculty members as a first step to better understand ML in the current context.

\section{Context}

Zayed University (ZU), founded in 1998, is one of the three government funded colleges in the United Arab Emirates (UAE). Zayed University has two campuses one in Dubai and one in Abu Dhabi - that offers scholarships to local students. The University invites both male and female students in independent locations as UAE customs suggest (http://www.zu.ac.ae).

In the undergraduate programs, the students are generally UAE nationals, who are enrolled in general education if they have an EMSAT English Score of 1250, or a scholastic IELTS score of 5.5, or a TOEFL iBT 71+ score. If students do not meet these requirements, they are admitted into the Academic Bridge Program (ABP), which is the English language foundations program, for 2 semesters until they are qualified to join the majors (http://www.zu.ac.ae). It is worth mentioning that literacy 
levels in the United Arab Emirates have greatly increased since the unification of the 7 Emirates in 1971. There is also a significant interest in female instruction as there is a genuine sense that teaching Emirati females will be an enormous advantage to the country due to the high need of Emiratization (Hojeij \& Hurley, 2017; MFNCA, 2009).

The current study focuses on faculty in the ABP and their experience with the iPad Initiative. The ABP started the iPad initiative in 2012. All students have personal devices and most of the content material is digital. They study 20 hours of English per week, from Sunday till Thursday, as weekend in UAE is Friday and Saturday. The university uses Blackboard as its learning management system, where all course content is stored, and assessments are distributed and marked. The university provides a strong WiFi connection for all students and faculty members to access with any devices they may have. Moreover, the university offer technical support to both faculty and students (Hojeij \& Baroudi, 2018). Faculty in the current study had not undertaken any previous formalized training in using the iPad as a teaching and learning tool prior to the ABP iPad initiative.

\section{$4 \quad$ Guiding Questions}

This study aims to look closely at mobile learning adoption specifically in public higher education in the context of the UAE through the collection and analysis of primary data to answer three main guiding questions. Answering these questions will determine the factors influencing faculty adoption and perceptions of using mobile learning tools in one public university in the UAE. To this end, this study will endeavor to answer the following research questions:

- To what extent is technology adopted by the teachers participants of this study?

- What do teachers perceive as the pedagogical benefits of mobile learning?

- What are the influencing factors that teachers identify for a succefful mobile learning

- Implementation?

\section{$5 \quad$ Significance of this Research}

The current study investigates and highlights the experience of 36 faculty members in the Academic Bridge Program, an English language foundation department, at a Zayed University in the UAE. Examining the challenges and benefits affiliated with the adoption of mobile learning technologies in this context will be of a great significance to better understand and deal with the factors affecting the public higher education section in the UAE. Therefore, this research aims to inform about the impact of mobile learning tools implementation as well as to investigate the faculty perceptions regarding such initiatives. Finally, while there is a large variety of apps being used in $\mathrm{ABP}$, the research is not app-specific but is rather concerned with the process of how 
mobile learning technology is being used to benefit the teaching and learning experience for all involved.

\section{$6 \quad$ Literature Review}

Several frameworks have emerged which focus on mobile learning, such as the SAMR (Substitution, Augmentation, Modification and Redefinition) Model, the TPACK (Technological Pedagogical Content Knowledge) model, the Frame model and the affordances model. Despite the existence of these frameworks, there is still a need for thorough research and solid frameworks which support mobile learning (Park, 2011). However, for the purpose of integrating mobile learning into a curriculum based on the program and to best fit students' and/ or teachers' needs, this study will adapt aspects of the FRAME model that could best support the research goals.

\subsection{The FRAME model}

According to Koole (2009), the different parts of the FRAME model can be divided into subsections that focus on the mechanics, learner involvement and the social aspects of mobile learning and how they overlap. The parts of the FRAME model are described in Table 1 below:

Table 1. Frame Model Characteristics

\begin{tabular}{|l|l|}
\hline \multicolumn{1}{|c|}{ The device aspect } & $\begin{array}{l}\text { Physical characteristics, input capabilities, output capabilities, } \\
\text { file storage and retrieval, processor speed and error rates }\end{array}$ \\
\hline The device usability intersection & $\begin{array}{l}\text { Portability, information availability, psychological comfort and } \\
\text { satisfaction }\end{array}$ \\
\hline The learner aspect & $\begin{array}{l}\text { Prior knowledge, memory, context and transfer, discovery learning, } \\
\text { emotions and motivations }\end{array}$ \\
\hline The social aspect & Conversation and cooperation and social interaction. \\
\hline The social technology intersection & Device networking, system connectivity, collaboration tools. \\
\hline The interaction learning intersection & Interaction, situated cognition and learning communities \\
\hline The Mobile Learning Process & $\begin{array}{l}\text { Includes mediation, information access and selection, and knowledge } \\
\text { navigation }\end{array}$ \\
\hline
\end{tabular}

These descriptors are identified as both individual and interrelated features that could better describe the status of mobile learning and the possible characteristics that lead to a successful mobile environment (Koole, 2009).

In addition to the FRAME Model, several affordances were highlighted by Cope and Kalantzis (2013) to include ubiquitous learning, feedback between stakeholders, production and creativity, learner autonomy, collaboration, reflection and differentiated instruction/learning. This study also drew on these affordances throughout this exploration. 


\subsection{Mobile learning integration}

Before integrating mobile learning, it is wise for educators to choose educational mobile applications that are suitable for the content and context. As such, Vincent (2012) explains that educators should consider customization and flexibility of the tools. For example, these applications should have features that provide feedback to students on their progress. In alignment with 21 st century skills, these applications should be designed to enhance students' higher order thinking skills through providing them with opportunities to create, evaluate and analyze. Moreover, he highlights that the most successful applications are the ones that engage the students and allow them to share either their specific performance summary or their product with the teacher or with their peers.

In a follow-up study to Vincent's (2012) work, research was conducted at a federal university in the United Arab Emirates in 2013, which reviewed these characteristics and adapted them based on teacher feedback (Eppard, Nasser \& Reddy, 2016). After collecting qualitative data through journals and focus groups, data was analysed based on Vincent's study and augmented using feedback from participating teachers to include the following benefits for mobile learning adoption: sharing, engaging, thinking skills, feedback, customization, relevance, culture, cost, ease-of-use and collaboration. As such, culture, cost, ease-of-use, and collaboration were specifically important characteristics to consider when choosing mobile learning tools in the current setting.

With that being said, there are several beneficial characteristics of mobile learning. These features can be divided into two key areas: pedagogy and resources. Pedagogically mobile learning lends itself to: ubiquitous learning, collaborative learning (Hamshire, O’Connor \& Crumbleholme, 2014), interactivity (Mehdipour \& Zerehkafi, 2013); differentiated learning (Park, 2011) including cultural relevancy (Ally, 2013). Ubiquitous learning is an important aspect of mobile learning (Mehdipour \& Zerehkafi, 2013). It is the notion that learning can take place at any time and at any place (Bradley \& Holley, 2011). There are several benefits to ubiquitous learning such as increasing autonomous learning. Ubiquitous learning engages learners in an environment where "Mobile devices and wireless Internet technology enable learners to learn using a variety of digital resources from anywhere in the world at anytime. This new way of learning is commonly known as ubiquitous learning or u-learning" (Hseieh, Jang, Hwang \& Chen, 2011, p. 1194).

Student performance is another advantage of mobile learning (Walker, 2013). For example, using mobile learning, an instructor and/or students can receive aggregate analytics (formative or summative) about their performances. Understanding student performance could contribute to an understanding of the success of mobile learning based on outcomes (Wagner et al., 2014). Many of these advantages are also true of elearning (desktop computers). However, given that mobile learning tools can be transported easily, these pedagogical affordances support the use of mobile learning for multiple scenarios. Finally, the agreement among researchers is that mobile learning tools have extensive pedagogical benefits in student-centered classrooms such as the above mentioned. Findings offer insights about the extent and impact of these benefits to both learners and teachers. Nevertheless, considering that a full literature review of 
the advantages is beyond the scope of the current study, additional domains have been mentioned in the literature as possible advantages for mobile learning in a studentcentered communicative classroom. These can be found in Table 2 below.

Table 2. Additional benefits of ML

\begin{tabular}{|c|c|c|}
\hline Reference & Benefits of ML & Summary \\
\hline $\begin{array}{l}\text { Hwang \& Chang, 2011; Koole, 2009; } \\
\text { Mehdipour \& Zerehkafi, } 2013 \\
\text { Damyanov, Tsankov, } 2018\end{array}$ & Interactivity & $\begin{array}{l}\text { - Fun and engaging to students } \\
\text { - Can provide students with ways to pro- } \\
\text { cess and apply new information } \\
\text { - Immersive experience. }\end{array}$ \\
\hline $\begin{array}{l}\text { Shih \& Mills, 2007; Ranieri \& Pachler, } \\
2014\end{array}$ & $\begin{array}{l}\text { Addressing learning } \\
\text { differences }\end{array}$ & $\begin{array}{l}\text { ML activities can be in different formats } \\
\text { (videos, infographics, eBooks, apps, etc.) } \\
\text { and different academic levels that are } \\
\text { easily accessible to all learners on various } \\
\text { mobile devices as a way to address learner } \\
\text { differences. }\end{array}$ \\
\hline Liu, Li \& Carlson, 2010 & Collaborative Learning & $\begin{array}{l}\text { Students can work together and help each } \\
\text { other using ML tools. They can engage in } \\
\text { peer feedback, collaborative work, discus- } \\
\text { sion boards, and so on. }\end{array}$ \\
\hline $\begin{array}{l}\text { Shadle, Perkins, Lincoln, Humphrey \& } \\
\text { Landrum, 2013; Mehdipour \& Zere- } \\
\text { hkafi, 2013; Backhouse, Wilson, \& } \\
\text { Mackley, 2014 }\end{array}$ & Student Engagement & $\begin{array}{l}\text { When learners are fully engaged, they are } \\
\text { involved in a more meaningful learning } \\
\text { experience. }\end{array}$ \\
\hline $\begin{array}{l}\text { Liu, Li \& Carlson, 2010; Zafar \& } \\
\text { Hasan 2014; Walker, 2013; Mehdipour } \\
\text { \& Zerehkafi, } 2013\end{array}$ & Student Motivation & $\begin{array}{l}\text { Learners are motivated because the experi- } \\
\text { ence of using ML tools is enjoyable. }\end{array}$ \\
\hline $\begin{array}{l}\text { Traxler, 2009; Naismith, Lonsdale, } \\
\text { Vavoula \& Sharples, } 2004\end{array}$ & Situated Learning & $\begin{array}{l}\text { Receiving help and timely feedback helps } \\
\text { students to take full advantage of their } \\
\text { learning experience }\end{array}$ \\
\hline Bradley \& Holley, 2011 & $\begin{array}{l}\text { Access to course } \\
\text { materials }\end{array}$ & $\begin{array}{l}\text { ML provides students with access to } \\
\text { chunks of knowledge depending on the } \\
\text { tools used. Larger platforms can provide } \\
\text { students with larger pieces of information. } \\
\text { ML tools can reach a large number of } \\
\text { learners in real time or offline allowing } \\
\text { them to engage in ubiquitous learning. }\end{array}$ \\
\hline Backhouse, Wilson, \& Mackley, 2014 & Reflective Processing & $\begin{array}{l}\text { Students are forced to reflect while engag- } \\
\text { ing in problem-solving. They can rely on } \\
\text { their prior knowledge and combine it with } \\
\text { the new information to reach a solution. }\end{array}$ \\
\hline $\begin{array}{l}\text { Hwang, Wu, Zhuang \& Huang, 2013; } \\
\text { Shih, Chuang, \& Hwang, } 2013\end{array}$ & $\begin{array}{l}\text { Inquiry-based Learn- } \\
\text { ing }\end{array}$ & $\begin{array}{l}\text { ML can include simulated experiences } \\
\text { which build confidence and sharpen prob- } \\
\text { lem-solving skills of learners. }\end{array}$ \\
\hline Kim, Mim \& Holmes, 2006 & $\begin{array}{l}\text { Sharing feedback } \\
\text { between teachers and } \\
\text { students }\end{array}$ & $\begin{array}{l}\text { ML allows teachers to provide real-time } \\
\text { feedback as well as digital feedback to the } \\
\text { learners in a variety of types (visual, audio, } \\
\text { video, etc.) }\end{array}$ \\
\hline Chuchu, Ndoro, 2019 & $\begin{array}{l}\text { Flexible and instant } \\
\text { access }\end{array}$ & $\begin{array}{l}\text { ML allows for students to access materials } \\
\text { ubiquitiiously and outside of the classes }\end{array}$ \\
\hline
\end{tabular}


As for the role of resources within Mobile Learning, it was discussed that mobile devices may be cheaper than other forms of technology (Park, 2011). While the device itself might be cheaper, the infrastructure needs to be in place (Shadle et al., 2013) giving both teachers and students ubiquitous access. Liu, Li \& Carlson (2010) state that one of the most important factors when considering mobile learning is its "long-term usefulness." Materials created for one tool on a specific device should be transferrable/ or able to be adapted to other devices/ tools accordingly without hidden or unexpected costs. Finally, another aspect of mobile learning that should be well thought out is content development (Liu, Li \& Carlson, 2010). Necessary materials should be easily accessible (Oliver, 2007) or content needs to be bought or prepared which could be costly and/or time consuming.

Despite the various advantages that mobile learning adoption offers to students and educators alike, it is worth noting that there are also several limitations. A great number of educators consider mobile devices as distractions in an educational context. Students can easily access games, messages or other apps which interrupt the classroom flow. In addition, teachers struggle to keep up with the latest technological advances which can adversely affect teachers' classroom management, teaching practices (Catapano, 2015; Costabile et al., 2008), and continuity (Oliver, 2007). Furthermore, adopting mobile learning without a clear pedagogical objective can be an impediment to learning/teaching in the classroom (Catapano, 2015). It was also argued that traditional assessments cannot always be applied using mobile technologies (Vavoula \& Sharples, 2008). Lastly, within the context of this study, Eppard, Nasser and Reddy (2016) found that mobile adoption could be limited due to poor design and expense in terms of both cost and time.

\section{$7 \quad$ Methodology}

In an effort to shed light on the benefits of mobile learning and the factors that influence the success of mobile learning implementation in the classroom, this study uses a concurrent mixed methods design. The ultimate aim of the current study was to use the information gathered from the literature review to develop a questionnaire to distribute to faculty. The survey gathered both quantitative (Likert-scale questions) and qualitative (open-ended questions) data.

\section{$8 \quad$ Participants}

The participants included instructors from the Academic Bridge Program, which is the pre-sessional English department at a federal university in the UAE. 53\% were instructors from the Dubai campus and $47 \%$ of the participants were teaching at the Abu Dhabi campus. The sample size existed of 56\% female teachers and $44 \%$ male teachers. The participants in the sample of the current study had many years of teaching experience: $8 \%$ of the teachers had 5-10 years of teaching experience, $58 \%$ had $10-15$ years of teaching experience while $33 \%$ of the participants had been teaching 
for more than 25 years. The faculty and their students have been using mobile learning in their classrooms for the past three years.

The faculty in this department was selected for this study as it has been officially using mobile learning as an instructional tool longer than any other department in the university. The iPad is integrated into the curriculum of each course. Therefore, it is assumed that these teachers are able to give a good estimation of the impact of mobile learning. The online survey link was distributed to 60 faculty members via email. 36 surveys were returned which makes the response rate $60 \%$.

\section{Data Collection}

Based on the literature review, a survey was developed by the researchers and sent electronically to the above described teachers of the English foundation program. Validity of the survey was tested through piloting and reliability was ascertained through repeated testing. The purpose of the pilot test was not to collect data but to determine if the questions made sense. The results achieved reliability through multiple stages of developing, checking and cross-checking categories, themes and responses.

Subjects agreed to participate in the study by accepting an online statement. Data from the subjects did not include information that could be tracked to the responder. The data were stored in an online survey platform that was protected by a username and password. The survey asked participants to provide feedback on the benefits and drawbacks of mobile learning. The survey was divided into the following sections: evidence, technology, teaching, resources, culture, and limitations. The survey At the end of each question, an open-ended section was added for subjects to explain their answers. This was used to gather the qualitative data.

\section{Data Analysis}

The data collected was processed and statistically analyzed through the Statistical Package for the Social Sciences (SPSS) Version 24. The three research questions for this study were explored by using descriptive statistics for the quantitative data. Additionally, qualitative thematic analysis was used to extract themes from the open-ended question in order to further elaborate on and create an in-depth understanding of the results from the quantitative analysis.

Results of the current study were derived from both quantitative and qualitative data. Quantitatively, the results relied on both descriptive statistics. Qualitatively, themes were extracted and analyzed from the open-ended questions. The results are presented below in relation to the guiding questions of the study. 


\section{Quantitative Analysis}

\subsection{To what extent is technology adopted by the teachers of this study?}

Considering the adoption of technology as a personal tool and a learning tool, only $8 \%$ of the participants reflected themselves very late adopters of technology as a personal tool, while $42 \%$ reported that they were late adopters. The remaining respondents were early adopters and innovators with a percentage of 28 and 22, respectively. None of the participants considered themselves skeptic towards the use of technology as a personal or teaching/learning tool. As for adopting technology as a teaching and learning tool, the numbers did not vary much. Only 6\% considered themselves very late adopters of technology as a personal tool, while 50\% reported that they were late adopters. The remaining respondents were early adopters and innovators at $22 \%$ each. The results can be seen in Table 3 below.

Table 3. Adoption of Technology as a personal and teaching/learning tool

\begin{tabular}{|l|c|c|c|c|c|c|}
\hline & Skeptic & $\begin{array}{c}\text { Very late } \\
\text { adopter }\end{array}$ & $\begin{array}{c}\text { Late } \\
\text { adopter }\end{array}$ & $\begin{array}{c}\text { Early } \\
\text { adopter }\end{array}$ & Innovator & N \\
\hline As a personal tool & $0 \%$ & $8 \%$ & $42 \%$ & $28 \%$ & $22 \%$ & 36 \\
\hline As a technology/learning tool & $0 \%$ & $6 \%$ & $50 \%$ & $22 \%$ & $22 \%$ & 36 \\
\hline
\end{tabular}

As for technology integration into teaching practice, the results varied from $39 \%$ of respondents using technology frequently in teaching to $11 \%$ who rarely use it. As expected, very late adopters for personal use showed the highest percentage of 'rarely use' (50\%). Late adopters for personal use showed the highest percentage of 'occasional use'. Early adopters had the highest percentage of 'frequent use' (38\%) and innovators |(49\%) scored 'almost always' on technology adoption for personal use.

The same pattern was shown in the results for technology adoption for teaching and learning. very late adopters for personal use showed the highest percentage of 'rarely use' (50\%). Late adopters for personal use showed the highest percentage of 'occasional use' (80\%). Early adopters had the highest percentage of 'frequent use' (38\%) and innovators mostly scored 'almost always' (63\%) on technology adoption for personal use. It can be concluded that the earlier teachers have adopted technology as a personal or teaching/learning tool, the more they eventually tend use it in their teaching practices.

\subsection{What do teachers perceive as the pedagogical benefits of mobile learning?}

The majority of informants replied that mobile learning had a positive impact on the teaching and learning process. The categories that indicate the highest positive impact were Ubiquitous Learning at $63.89 \%$, Interactivity at $61.11 \%$, and Teacher/Student Feedback at 55.56\%. The lowest positive impact was in the Situated Learning at $33.33 \%$. The results arwe presented in Table 4 below. 
Table 4. Mobile Learning impact

\begin{tabular}{|l|c|c|c|c|c|}
\hline & Yes & No & Maybe & N/A & N \\
\hline Student Engagement & $50 \%$ & $16.67 \%$ & $30.56 \%$ & $2.78 \%$ & 36 \\
\hline Interactivity & $61.11 \%$ & $2.78 \%$ & $33.33 \%$ & $2.78 \%$ & 36 \\
\hline Formative and/or Summative Assessments & $44.44 \%$ & $8.33 \%$ & $41.67 \%$ & $5.56 \%$ & 36 \\
\hline Students with Learning Differences & $41.67 \%$ & $11.11 \%$ & $38.89 \%$ & $8.33 \%$ & 36 \\
\hline Teacher/Student Feedback & $55.56 \%$ & $5.56 \%$ & $30.56 \%$ & $8.33 \%$ & 36 \\
\hline Ubiquitous Feedback & $63.89 \%$ & $5.56 \%$ & $25 \%$ & $5.56 \%$ & 36 \\
\hline Situated Learning & $33.33 \%$ & $25 \%$ & $36.11 \%$ & $5.56 \%$ & 36 \\
\hline Inquiry-Based Learning & $41.67 \%$ & $22.22 \%$ & $33.33 \%$ & $2.78 \%$ & 36 \\
\hline
\end{tabular}

\subsection{What are the influencing factors that teachers identify for mobile learning implementation?}

The questionnaire inquired about factors that teachers consider and prior to selecting an app for use as a learning tool in the classroom. The two considerations that were explored are the evidence of app effectiveness and cultural influences and appropriateness. $44 \%$ of teachers indicated that it is not important for them to select an app for which conclusive evidence showed a significant positive effect on student learning outcomes. 33\% of the participants answered 'Maybe' and 17\% replied that evidence is important for them. In contrast to this, a relatively high percentage of participants (75\%) specified that they consider cultural influences and appropriateness before choosing an app to use in their learning contexts, specifically if it suits their students and their learning environment. In contrast, only $6 \%$ said that cultural appropriateness is not an important factor for them to consider. The results of both factors can be seen in Figures 1 and 2 below.

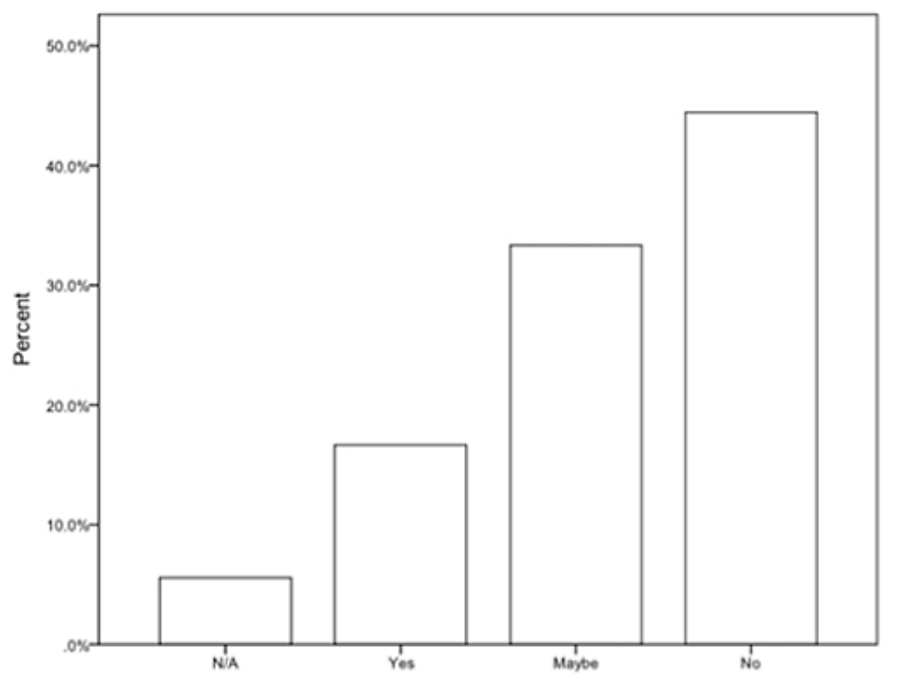

Fig. 1. Importance of evidence before adoption 


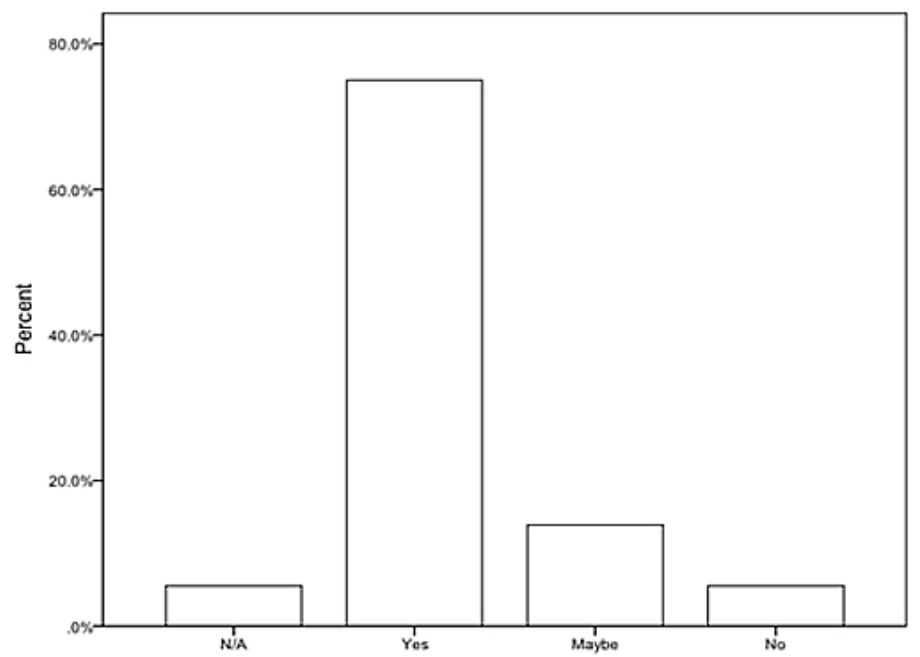

Fig. 2. Consideration of cultural influences before adoption

Additional considerations can be seen in Table 5 below. Participants indicated that before choosing a new app to use in class, they consider 6 additional factors. The most important consideration is Content Delivery at $69.44 \%$, followed by Cost and Content Sharing at $58.33 \%$ each, then Use across Devices at $52.78 \%$, Maintenance at $47.22 \%$ and Training as the least important at $44.44 \%$.

Table 5. Considerations before applications choice

\begin{tabular}{|l|c|c|c|c|c|}
\hline & Yes & Maybe & No & N/A & N \\
\hline Training & $44.44 \%$ & $27.78 \%$ & $19.44 \%$ & $8.33 \%$ & 36 \\
\hline Cost & $58.33 \%$ & $16.67 \%$ & $5.56 \%$ & $19.44 \%$ & 36 \\
\hline Maintenance & $47.22 \%$ & $25 \%$ & $13.89 \%$ & $13.89 \%$ & 36 \\
\hline Use across devices & $52.78 \%$ & $25 \%$ & $13.89 \%$ & $8.33 \%$ & 36 \\
\hline Content Sharing & $58.33 \%$ & $30.56 \%$ & $2.78 \%$ & $8.33 \%$ & 36 \\
\hline Content Delivery & $69.44 \%$ & $16.67 \%$ & $2.78 \%$ & $11.11 \%$ & 36 \\
\hline
\end{tabular}

\section{Qualitative Analysis}

Providing context for the quantitative answers, participants expanded on their responses through open-ended qualitative comments in the provided sections of the survey. Five themes emerged from the qualitative portion of the data: training, cost, appropriateness (cultural and language level), classroom management, and student engagement. 


\subsection{Training}

Some teachers mentioned that training in the use of apps and technological tools could be another factor that might influence the success of mobile learning implementation in the classroom. One respondent emphasized the need for comprehensive training and indicated that training could be problematic because "Training (is) rarely sufficient to self-evaluate to learn by oneself and then train other users."

\subsection{Cost}

Secondly, cost should also be considered as an important factor in technology adoption. One subject stated "if apps are free then we use them, if they are not then we don't". When the students are obliged to pay for an app, the teachers are inhibited to use this app in their teaching practices. Sharing information is also a major consideration and believed to be important for successful implementation. One respondent stated that: "Being able to upload and share information is a major factor of whether the app is usable. I prefer to work within a closed environment where the multiplatform use of the device is less of a consideration."

\subsection{Appropriateness}

In responding to the question of appropriateness, faculty had to consider two subcategories: 1) The second language level of learners, and 2) the culture of the learners. The results showed that $75 \%$ of respondents indicated the importance of appropriateness when choosing an app for the classroom. This suitability takes into consideration the students as well as the environment. One faculty member stated, "Many apps are designed for English language speakers that are far above my students' level so they need to be carefully examined before use in the classroom." This is a clear implication of the relationship between the English language level of the learners and how much benefit they gain from an app in class. Moreover, when looking at the importance of the local culture when choosing an app, one participant indicated that, "The students are the priority, not the apps. It's the students who have to learn in their own environment. Of course, appropriateness and culture are always considered before using materials in class". Given the local conservative culture in the UAE, it is essential that any app chosen adhere to the norms and values of the learners and their society.

\subsection{Classroom Management}

Many of the respondents were concerned about classroom management. They seemed to be worried that users would be distracted during lessons by using apps when they should be focusing on their lesson. One comment highlighted this possible belief, "Let them have their phones out and they are off on Instagram. (It is) impossible to keep many students on task, but I think it gets better as they move up in their university careers". This comment alludes to the possible change in student behavior 
as they move through the university system or if they are placed out of the presessional program. This is an idea that will be explored in subsequent studies.

\subsection{Student Engagement}

The fifth emerging theme based on the respondents' comments was student engagement, which was found to be beneficial in the quantitative section as well. This was supported in the following comment, "If students enjoy it and it engages them, it helps them with the task at hand, and then it's useful." In addition, two possible limitations were highlighted: 1) difficulties with writing on the iPad and 2) lack of student responsibility. One subject stated "generally ALL apps have limitations of inputting text or by writing on the screen." Another comment indicated, "Students sometimes forget to charge or bring their device".

Moreover, there were mixed responses about choosing apps based on research. The following comments were more varied with respondents stating that research is more important and others saying that it is not that crucial. However, the overall majority indicated that research and conclusive evidence are not important. Subjects who supported possibly choosing apps based on conclusive evidence stated, "Depends on how they are used, better if teachers know the evidence so they do not lose time experimenting." Another said, "Evidence needs to be sound if apps are mandated". One more comment stated, "It is an expensive and time consuming tool to implement and should be validated before it is used in the classroom". Other comments showed that research could be important but that everything should be viewed based on the context: "the context is more important than evidence from other contexts." Arguing further that research is not always needed, one opinion in a comment stated, "If we always wait for evidence, we will be very backward technology wise. Also, some positive outcomes are hard to quantify in terms of evidence because they are motivation related."

\section{Discussion}

Based on a review of the literature, there are several factors that need to be considered before mobile learning is put into effect. For example, in order for stakeholders to experience the maximum benefits of ML, there should be both input and output capacities, the ability to file and retrieve information, the processor should be quick, and the device should be portable. In addition, items created on one device should be easily transferred to another device. Previous research also states that teacher training is important, as are design and sustainability. Culture is another area that needs to be addressed as well. To this end, the scope of the current research was to further investigate how higher education teachers in the UAE perceive the usefulness of Mobile Learning technologies. Data was analyzed using both quantitative and qualitative techniques in order to answer the research guiding questions. 


\subsection{To what extent is technology adopted by the teachers of this study?}

Based on the data collected in this study, it was found out that most of the teachers reported being late adopters of technology both as a learning tool and for personal use. However, these teachers conveyed that they maintained ML a useful device as a learning tool. Hence, it could be concluded that these teachers value the usefulness of technology integration into their classrooms. As such, teachers beliefs and perceived value of technology integration are not regarded as a barrier in this context as it was found in the early literature on Mobile learning (Ertmer, 1999).

\subsection{What do teachers perceive as the pedagogical benefits of mobile learning?}

The current study explored the perceptions of teachers on the benefits of mobile learning. Therefore, teachers were asked to evaluate the effectiveness on different aspects of teaching and learning: student engagement, interactivity, formative and/or summative assessments, students with learning differences, teacher/student feedback ubiquitous learning, situated learning and inquiry-based learning. Teachers reported that mobile devices could support student learning in all areas indicated. Similar to other contexts, participants of this study rated Ubiquitous learning beneficial towards teaching and learning process in comparaison with situated learning. This is aligned with previous studies that have already shown how ubiquitous learning is considered to be an important aspect of mobile learning (Mehdipour \& Zerehkafi, 2013).

Furthermore, it is important for teachers to be convinced of the positive contribution of technology towards teaching and learning context as a catalyst for its successful implementation (Bitner \& Bitner, 2002). Of all areas, participants in this study had the least confidence in the benefits of mobile learning on situated learning. This is due to that situated learning takes places in the context of realistic settings, in which technology might play a less important role than it does in areas which focus on interactive learning for instance (Traxler, 2009).

\subsection{What are the influencing factors that teachers identify for successful mobile learning implementation?}

Based on the responses of both quantitative and qualitative items, the participants perceived cultural considerations as highly important. Teachers discussed the necessacity of considering students context (i.e, language) as well as the environment for a successful technology integration. The UAE in general places importance on cultural appropriateness (Palmer, 2013). With that being said and given the local conservative culture in the UAE, it is essential that any app chosen adheres to the norms and values of the learners and their society.

Furthermore, almost all participants considered teacher training, cost and maintenance of the apps, as additional factors that will facilitate the selection process of mobile apps. Participants reported that for these mobile apps to be aligned with the learning objectives, they should be usable across devices and expedite content sharing and delivery. Interestingly, participants revealed classroom management as an addi- 
tional influential factor that could affect mobile learning integration. That is why, training these teachers on how to integrate technology inside the classroom would help alievate this issue while keeping them up-to-date on best practices (Catapano, 2015; Oliver, 2007).

Despite that the majority of participants indicated that ML is a useful teaching tool, they also stated that mobile devices can lead to distractions in the classrooms. This finding aligns with Catapano (2015) and Costabile et al. (2008) who argued that mobile technologies could cause students to lose focus. Additional disadvantages were idendified as

- Frequent updates and changes which create a continuous knowledge gap and difficulties with staying current

- Network coverage can sometimes be problematic

- A lack of purpose with using mobile technologies in the classroom. Ertmer (1999) discussed several strategies that the school could follow to overcome these barriers

As such, articulating an overall vision for classroom technology use is fundemantal for its effectivness and sustainability.

\section{Conclusion}

Widely adopting a new technology into an educational environment can sometimes seem confusing and may therefore receive pushback and eventual abandonment from instructors. Thus, it is vital that administrators follow the adoption of the technology and the way that supports classroom instruction. Studies show that when tablet devices are used correctly, they bring about numerous benefits such as mastery of learning, collaboration, and critical thinking (Kumi-Yeboah \& Campbell, 2015). This paper demonstrates how teachers can provide essential feedback that can be used to make decisions to insure that ML implementation is applied correctly.

\section{Limitations}

The limitations of this paper include, but are not limited to the following:

- First, the project is limited to only one department in the university. This does not allow for comparison between departments and so the results cannot be generalized.

- The second limitation is the sample population size. Although the initial data collected was from over 60 faculty members, only 36 responses were complete and could be included in the study. The small number of participants can impose limitations on the generalizations of results.

- The third limitation is the consistency of apps used by faculty. As there are no guidelines of required apps to be used by instructors, there is a very wide range of apps used for various purposes. 
- The final limitation is classroom management in relation to the gender of the students. As there are two separate programs for females and males, respondents from each program have different classroom management issues in relations to using apps in their classes. As such, their views are based on their personal experiences in teaching either males or females and not mixed classes.

\section{Recommendations for Future Studies}

The current study aims to offer a comprehensive view of mobile learning in higher education in the UAE. To provide a deeper analysis of this topic, further research could investigate students' academic achievement in relation to mobile learning to determine its impact. Moreover, more than one department or college should be involved in the data collection to increase the reliability of the study. More research is also recommended to explore the cultural norms of local contexts and how ML apps are integrated in different environments. In addition, research could include data about students' personal devices for learning purposes. Finally, further studies could include the development of a rubric with specific criteria for app evaluation, which could support faculty in choosing apps as teaching/learning tools.

This study focuses primarily on the use of mobile devices, specifically the iPad, for educational purposes as a starting point for this context. More research needs to be conducted on the implementation of flipped learning and blended learning in the same environment.

\section{References}

[1] Ally, M. (2013). Mobile learning: from research to practice to Impact Education. Learning and Teaching in Higher Education: Gulf Perspectives, 10(2), 46-63.

[2] Backhouse, A., Wilson, I., \& Mackley, D. (2014). Enhancing the formative assessment

[3] environment through the use of mobile technologies. Good Practice Guide - Mobile Learning: How Mobile Technologies can Enhance the Learning Experience, 24.

[4] Baran, E. (2014). A Review of Research on Mobile Learning in Teacher Education. Educational Technology \& Society, 17(4), 17.

[5] Bitner, N., \& Bitner, J. O. E. (2002). Integrating technology into the classroom: Eight keys to success. Journal of Technology and Teacher Education, 10(1), 95-100

[6] Bradley, C., \& Holley, D. (2011). Empirical research into students' mobile phones

[7] and their use for learning. International Journal of Mobile and Blended Learning (IJMBL), 3(4), 38-53. DOI:10.4018/jmbl.2011100103.

[8] Catapano, J. (2015). Advantages/Disadvantages of the iPad Classroom. Retrieved

[9] from http://www.teachhub.com/advantagesdisadvantages-ipad-classroom on April 10, 2015.

[10] Cheon, J., Lee, S., Crooks, S. M., \& Song, J. (2012). An investigation of mobile learning readiness in higher education based on the theory of planned behavior. Computers \& Education, 59(3), 1054-1064. https://doi.org/10.1016/j.compedu.2012.04.015 
[11] Chuchu, D., \& Ndoro, T. (2019). An examination of the determinants of the adoption of mobile application as learning tools for higher education students. International Journal of Interactive Mobile Technologies. 13(3), 53-67. https://doi.org/10.3991/ijim.v13i03.10195

[12] Cornforth, D. (2012). Frameworks for mobile learning. Retrieved from

[13] https://mobilelearninginfokit.pbworks.com/w/page/41753215/Frameworks\%20for\%20mob ile\%20learning?mode=embedded on April 5, 2017

[14] Cope, B., \& Kalantzis, M. (2013). Towards a new learning: The scholar social knowledge workspace, in theory and practice. E-Learning and Digital Media, 10(4), 332-357. https://doi.org/10.2304/elea.2013.10.4.332.

[15] Costabile, M. F., De Angeli, A., Lanzilotti, R., Ardito, C., Buono, P., \& Pederson, T. (2008, April). Explore! possibilities and challenges of mobile learning. In Proceedings of the SIGCHI Conference on Human Factors in Computing Systems(pp. 145-154). ACM. https://doi.org/10.1145/1357054.1357080

[16] Damyanov, I., \& Tsankov, N. (2018). Mobile apps in daily learning activities. International Journal of Interactive Mobile Technologies. 12(6), 133-140. https://doi.org/10.3991/ijim.v $\underline{12 \mathrm{i} 6.9659}$

[17] Eppard, J., Nasser, O., \& Reddy, P. (2016). The Next Generation of Technology: Mobile Apps in the English Language Classroom. International Journal of Emerging Technologies in Learning, 11(4). https://doi.org/10.3991/ijet.v11i04.5293

[18] Ertmer, P.A. (1999). Addressing first-and second-order barriers to change:strategies for technology imntegration. Educational Technology Research and Development, 47(4), 4761. https://doi.org/10.1007/bf02299597

[19] Hamshire, C., O’Connor, D., \& Crumbleholme, H. (2014) Padding around-using iPads to promote collaborative learning. Good Practice Guide Mobile Learning: How Mobile Technologies can Enhance the Learning Experience, 6.

[20] Hojeij, Z., \& Baroudi, S. (2018). Student perceptions on peer feedback training using a blended method: A UAE case. Issues in Educational Research, 28(3), 655.

[21] Hojeij, Z. \& Hurley, Z. (2017). The Triple Flip: Using Technology for Peer and SelfEditing of Writing. International Journal for the Scholarship of Teaching and Learning: 11(1), Article 4. https://doi.org/10.20429/ijsotl.2017.110104

[22] Hsieh, S., Jang, Y., Hwang, G., Chen, N. (2011). Effects of teaching and learning styles on students' reflection levels for ubiquitous learning. Computers \& Education, 57(1), 11941201. https://doi.org/10.1016/j.compedu.2011.01.004

[23] Hwang, G., \& Chang, H. (2011). A formative assessment-based mobile learning approach to improving the learning attitudes and achievements of students. Computers \& Education, 56(4), 1023-1031. https://doi.org/10.1016/j.compedu.2010.12.002.

[24] Hwang, G. J., Wu, P. H., Zhuang, Y. Y., \& Huang, Y. M. (2013). Effects of the inquirybased mobile learning model on the cognitive load and learning achievement of students. Interactive Learning Environments, 21(4), 338-354. https://doi.org/10.1080/10494820.201 1.575789 .

[25] Kerrigan, M., Blackburn, R., Force, S., Amin, Z., James, K., Yorke, J., Walter, S.; Snowden, M. \& Scott- Jones, E. (2014). The student experience of using iPads to enhance undergraduate laboratory teaching. UCISA (2014) Good Practice Guide. Mobile Learning: How Mobile Technologies can Enhance the Learning Experience, 31-38.

[26] Kim, S. H., Mim, C., \& Holmes, K. P. (2006). An introduction to current trends and benefits of mobile wireless technology use in higher education. AACE Journal, 14(1), 77-100.

[27] Koole, M. (2009). A model for framing mobile learning. In M. Ally (Ed.), Mobile learning: Transforming the delivery of education and training (pp. 46-70). Edmonton: Athabasca University Press. 
[28] Kumi-Yeboah, A., \& Campbell, K. S. (2015). Emerging use of tablets in K-12 environments: issues and implications in K-12 schools. In Tablets in K-12 education: Integrated experiences and implications (pp. 46-63). IGI Global. https://doi.org/10.4018/97 8-1-4666-6300-8.ch004

[29] Liu, Y., Li, H., \& Carlson, C. (2010). Factors driving the adoption of m-learning: An empirical study. Computers \& Education, 55(3), 1211-1219. https://doi.org/10.1016/j.co mpedu.2010.05.018.

[30] MacCallum, K., Jeffrey, L., \& Kinshuk, K. (2014). Factors impacting teachers' adoption of mobile learning. Journal of Information Technology Education, 13,141-162.

[31] Mehdipour, Y., \& Zerehkafi, H. (2013). Mobile learning for education: Benefits and challenges. International Journal of Computational Engineering Research, 3(6), 93-101.

[32] Naismith, L., Lonsdale, P., Vavoula, G., Sharples, M., \& Series, N. F. (2004). Literature review in mobile technologies and learning. Citeseer. A NESTA Futurelab Series - report 11.

[33] Oliver, R. (2007). Using mobile technologies to support learning in large on campus university classes. Proceedings Ascilite Singapore, Singapore, 788-798.

[34] Palmer, B. M. (2013). Culture in the EFL Classroom: Western Instructors and Arab Students in the UAE (Doctoral dissertation, American University of Sharjah).

[35] Park, Y. (2011). A pedagogical framework for mobile learning: Categorizing educational applications of mobile technologies into four types. The International Review of Research in Open and Distance Learning, 12(2). Available online at: http://www.irrodl.org/index.php/irrodl/article/view/791/1699 https://doi.org/10.19173/irro dl.v12i2.791

[36] Ranieri, M., \& Pachler, N. (2014). Inventing and reinventing identity: exploring the potential of mobile learning in adult education. Prospects, 44, 61-79. https://doi.org/10.10 07/s11125-014-9294-1.

[37] Shuler, P., Hutchins, G., \& LaShell, B. (2010). Student perceptions of tablet computers in a cooperative learning environment. NACTA Journal, 54(2), 11-17.

[38] Shadle, S., Perkins, R., Lincoln, D., Humphrey, M., \& Landrum, E. (2013, June). A multifaceted, organic approach to a campus-wide mobile learning initiative: The case of Boise State University. In EdMedia: World Conference on Educational Media and Technology (pp. 665-672). Association for the Advancement of Computing in Education (AACE).

[39] Shih, Y. E., \& Mills, D. (2007). Setting the New Standard with Mobile Computing in Online Learning. The International Review of Research in Open and Distributed Learning, 8(2). https://doi.org/10.19173/irrodl.v8i2.361

[40] Shih, J., Chuang, C., \& Hwang, G. (2010). An inquiry-based mobile learning approach to enhancing social science learning effectiveness. Educational Technology \& Society, 13(4), 50-62.

[41] Traxler, J. (2009). Learning in a mobile age. International Journal of Mobile and Blended Learning (IJMBL), 1(1), 1-12. DOI:10.1111/jcal.12036.

[42] Vavoula, G.N., Sharples, M. (2008). Challenges in Evaluating Mobile Learning' in Traxler, J., Riordan, B., Dennett, C. (Eds) Proceedings of the mLearn 2008 Conference. School of Computing and Information Technology, University of Wolverhampton, pp. 296-303.

[43] Vincent, T. (2012, March 4). Ways to Evaluate Educational Apps. [Web log comment] Retrieved from http://learninginhand.com/blog/ways-to-evaluate-educational-apps.html

[44] Wagner, D. A., Castillo, N. M., Murphy, K. M., Crofton, M., \& Zahra, F. T. (2014). Mobiles for literacy in developing countries: An effectiveness framework. Prospects, 44(1), 119-132. https://doi.org/10.1007/s11125-014-9298-x. 
[45] Walker, H. (2013). Establishing content validity of an evaluation rubric for mobile technology applications utilizing the Delphi model (Doctor of Education). Retrieved from https://jscholarship.library.jhu.edu/bitstream/handle/1774.2/36935/WALKER-DISSERTA TION-2013.pdf

[46] Zafar, A., \& Hamid Hasan, S. (2014). Towards contextual mobile learning. International Journal of Modern Education and Computer Science, 6(12), 20-25. https://doi.org/10.5815/ ijmecs.2014.12.03

\section{Authors}

Jenny Eppard has a PhD in Instructional Technology from the University of Virginia in USA and a Master's degree in International Education from George Washington University. Her research interests include flipped learning, XMOOCs in UAE, online collaborative tools for content reading, vocabulary centered Apps, e-portfolios, interactive documentaries and online learning.

Zeina Hojeij holds an EdD in Educational Leadership and Administration from Saint Louis University, MI, USA. She is a Fellow of the Higher Education Academy. Additionally, she is a Certified Online Instructor, CELTA \& CELTYL certified. Her research interests include mobile learning technology, educational leadership, applied linguistics and teaching \& learning.

Pinar Ozdemir Ayber holds a BA in English Language and Literature from Hacettepe University, Turkey and a masters in TESOL from Aston University. She is a certified NLP practitioner and an IELTS examiner. She is also a Fellow of the Higher Education Academy. Her research interests include teacher feedback, development and evaluation of language teaching materials, and Mobile Learning.

Marlieke Rodjan-Helder is a research assistant based at Zayed University in Dubai. She holds a Master's Degree in Behavioural and Educational Sciences from the VU University Amsterdam, the Netherlands. She is involved with research projects in the areas of educational technology, teaching and learning methodologies, inclusive education and special needs.

Sandra Baroudi is a PhD candidate in Educational Leadership and Management at the British University in Dubai, UAE. She also holds a master's degree in Educational Leadership and Management from Zayed University, UAE. Her research interests include educational leadership, educational policy and management, technology in education, and teaching and learning.

Article submitted 2019-05-08. Resubmitted 2019-07-08. Final acceptance 2019-07-10. Final version published as submitted by the authors. 